положительных и нежелательных эффектов. Рассмотрены возможности снижения затрат на производство сдобных хлебобулочных изделий с использованием пароконвектомата на предприятиях социальной сферы (в школьных столовых).

$$
* * *
$$

1. Маклаков С.В. Моделирование бизнес-процессов с BPWin, - М: Диалогмифи, 2002 - 209 с.

2. Принятие решений. Метод анализа иерархий / Т. Л. Саати ; пер. с англ. Р. Г. Вачнадзе Саати, Томас Л. М. : Радио и связь , 1993

3. Мезенцев Ю.А., Преображенская Т.В. Функционально-стоимостный анализ. Инструменты и модели: учебное пособие. - Новосибирск: Изд-во НГТУ, 2003.- 122с. Библиография в учебном пособии.

4. Применение метода функционально-стоимостного анализа на этапе разработки хлебобулочных изделий. Маюрникова Л.А., Уржумова А.И., Клишина М.Н.// Индустрия питания. 2017. № 2 (3). С. 70-77.

\title{
Строкова A.P.
}

\section{Современные механизмы стимулирования трудовой деятельности работников}

Белгородский государственный технологический университет им. В.Г. Шухова (Россия, Белгород)

doi:10.18411/spc-8-03-2018-25

idsp: 000001:spc-8-03-2018-25

Научный руководитель: Хорошун Н.А.

Наверное, трудно найти сейчас такую современную компанию или организацию, в которой не применялось бы стимулирование труда персонала. Как известно, изучение и совершенствование методов стимулирования началось давно и продолжается до сих пор. С развитием общества потребности и предпочтения людей постоянно меняются. Вследствие чего с каждым годом разрабатываются и применяются на практике новые механизмы и способы воздействия на работников с целью улучшения их трудовой деятельности.

Вероятнее всего, для большинства сотрудников любой фирмы главным вознаграждением за его труд будет являться материальное стимулирование. Оно в свою очередь делится на два вида:

1) материально-денежное стимулирование, которое включает такие формы, как заработная плата, бонусы, премии, участие в прибылях;

2) материально-неденежное стимулирование, состоящее из различных социальных программ, предоставления разнообразных путевок для сотрудников, оплаты проезда, льгот и компенсаций.

Но ведь вознаграждение - это то, что человек считает для себя ценным, поэтому не для всех людей материальное поощрение будет иметь первостепенное значение. По этой причине опытные руководители нередко используют в своей управленческой деятельности нематериальные стимулы [2, с. 261]. Для наглядного восприятия перечисленные виды стимулирования труда персонала можно увидеть на рисунке 1.

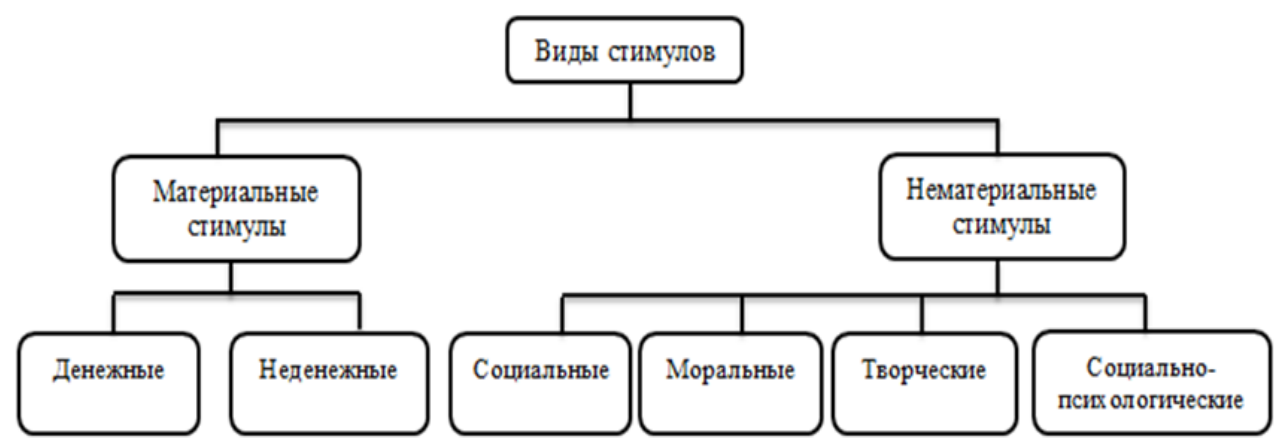

Рис. 1. Виды материальных и нематериальных стимулов 
Какой из видов стимулов выбрать решает руководитель в соответствии с той системой стимулирования, которая сложилась и закрепилась на предприятии. С помощью уже выработанного комплекса мероприятий воздействие на трудовую деятельность персонала будет эффективнее и приведет к значительному увеличению производительности труда. Здесь важно идти в ногу со временем, поскольку люди всегда нуждаются не только в качественном и полезном товаре (услуге), но и в актуальном [3, с. 181].

Исходя из этого, хочется сказать, что добиться нужных стандартов в выпускаемой продукции или предоставляемой услуге, можно только с помощью трудоспособных и настроенных на успех работников [1, с. 99].

На сегодняшний момент можно найти достаточно большое количество современных способов стимулирования труда персонала. Одним из таких является игрофикация, или геймификация, - новый подход в управлении персоналом, начало которого было положено в 2000 году. Геймификация представляет собой использование игровых методов в мотивации и стимулировании работников. По мнению разработчиков, данный метод является наиболее простым и интересным, так как предполагает разрешение сложившихся рабочих ситуаций посредством игровых технологий.

Такой подход включает командообразующие тренинги, деловые игры, бизнес кейсы, прохождение различных тестов и многие другие игровые элементы и формы. В результате геймификации складывается особая обстановка, в которой сотрудники компании проявляют наибольшую активность при решении различных задач. Помимо этого, возрастает сплоченность группы, налаживается социально-психологический климат в коллективе. Реализация подобных игровых ситуаций способствует отличному настроению работников, хорошему расположению духа и сближению со своими коллегами.

Другим известным методом стимулирования является предоставление различных путевок на отдых, например, в пансионаты, санатории, на море и в детские лагеря. За свои заслуги в трудовой деятельности работник может получить подобную путевку. Такой отдых дает сил и заряжает энергией на весь год, вследствие этого повышается работоспособность и производительность труда персонала. Но, к сожалению, не все компании могут позволить себе подобный метод стимулирования, так как он требует определенных затрат.

Еще одним интересным и современным механизмом стимулирования труда считается социальная карта. Она подразумевает создание виртуального счета, который должен быть у каждого работника. В течение трудовой деятельности в зависимости от занимаемой должности сотруднику фирмы может быть начислена конкретная денежная сумма. Возможности ее использования и применения ограничены услугами, которые предусмотрены социальной картой и предоставлены компанией, поэтому обналичить эти деньги нельзя. Потратить, заработанные средства можно, например, на поддержание и охрану своего здоровья благодаря посещению медицинских учреждений, на дополнительный отпуск или на выплату материальной помощи, а также на получение премий, предусмотренных организацией. Это очень хороший и действенный способ воздействия на работников, поскольку предполагает материальное поощрение, в котором нуждаются многие.

Подводя итог, хочется сказать, что современных механизмов стимулирования трудовой деятельности персонала сегодня насчитывается большое количество. Все они призваны воздействовать на человека с определенной целью, будь то повышение производительности труда, улучшение работоспособности или налаживание социально-психологического климата в коллективе.

$$
* * *
$$

1. Кравченко Е.Ю., Лахнова В.В. Современные подходы к стратегическому анализу в менеджменте // Белгородский экономический вестник. 2016. №4 (84). С. 97-102. 
2. Хорошун Н.А., Шамаева О.П., Избирян Л.В. Оценка деловой активности предприятия: золотое правило экономики // Вестник БГТУ им. В.Г. Шухова. 2017. №11. С. 260-265.

3. Хорошун Н.А., Шамаева О.П. Кадровая политика как часть стратегически ориентированной политики организации // Инновационная наука. 2016. № 1-3 (13). С. 178-183.

\section{Щербина К.О. \\ Развитие инструментария оптимизации и реинжиниринга бизнес-процессов}

Кубанский государственный университет

(Россия, Краснодар)

doi:10.18411/spc-8-03-2018-26

idsp: 000001:spc-8-03-2018-26

В последние годы Управление бизнес-процессами (ВРМ) получает значительное внимание со стороны многих организаций. Бизнес-лидеры все больше и больше сосредоточены на кросс-функциональных бизнес-процессах, а не на управлении слабо связанными функциями. Все больше и больше процесс-ориентированных организаций развиваются, чтобы достичь новых границ повышения производительности.

Внынешнейглобальнойконкурентнойсреде,компаниипостоянностремятся дифференцировать свою деятельность новыми, более быстрыми иещеболееценными предложениями нарынках,в рамках которых они осуществляют свою деятельность.Компаниииспользуютбизнес-процессы

дляинкапсуляциидействий,необходимых длясоздания ценности для заинтересованныхсторон.Бизнес-процессыстановятся фундаментом для компаний при создании конкурентных преимуществ или дифференцировании бизнеспредложения.Бизнес-процессыпомогают компаниям понять,измеритьиопиратьсянасуществующуюпрактику,чтобысоздатьновыеилиулучшен ныеметоды.

Управление бизнес-процессами (BPM-businessprocessmanagement) рассматривает материальные, трудовые и информационные ресурсы во взаимодействии друг с другом. Управление бизнес-процессом взаимосвязанных подразделений предприятия, как единым целым, является ключевым моментом данной концепции.

Компании применяют технологические решения ВРМ для различных целей. Доминирующей же причиной является необходимость маневренности и повышения эффективности бизнеса в условиях развивающихся бизнес-задач в глобальной бизнессреде. Технологические решения ВРМ помогают воспроизводить инновации, позволяющие повышать их ценность для клиентов. Другие причины компании, принимающие решения ВРМ, включают повышенную производительность, улучшенное качество, инновации, улучшение соблюдения и прозрачность, способность реагировать на изменения рынка и многое другое.

Реинжиниринг - это фундаментальное переосмысление и радикальное перепроектирование бизнес-процессов компаний для достижения коренных улучшений в наиболее важных показателях их деятельности - стоимость, качество и темпы. Данное определение было сформулировано М. Хаммером и Дж. Чампи, но в более современных трудах и на практике требование радикальности стало смягчаться. Это обусловлено сложностью определения степени радикальности преобразований в отдельно взятой ситуации. В связи с этим можно сформулировать еще одно определение реинжиниринга, согласно которому он представляется, как кардинальное изменение существующей структуры управления и производства компании, основанного, как и в инжиниринге, на взаимодействии выбранных процессов.

BPR - методика реструктуризации бизнеса, применяемая во всем мире, опирающаяся на бизнес-процессы, и позволяющая обеспечить значительные улучшения в течение короткого периода времени. Методика реализует организационные изменения, основанные на тесной координации методологии для быстрого изменения, расширения прав и возможностей сотрудников и обучению и 